\title{
Clinical-epidemiological profile of children with schistosomal myeloradiculopathy attended at the Instituto Materno-Infantil de Pernambuco
}

\author{
Karina Conceição GM Araújo/ ${ }^{+}$, Cristiana da Rosa e Silva, Constança Simões Barbosa, \\ Teresa CA Ferrari*
}

\author{
Laboratório de Esquistossomose, Centro de Pesquisas Aggeu Magalhães-Fiocruz, Av. Moraes Rego s/nº, \\ Cidade Universitária, 50670-420 Recife, PE, Brasil *Departamento de Clínica Médica, Faculdade de Medicina, \\ Universidade Federal de Minas Gerais, Belo Horizonte, MG, Brasil
}

The most critical phase of exposure to schistosomal infection is the infancy, because of the more frequent contact with contaminated water and the immaturity of the immune system. One of the most severe presentations of this parasitosis is the involvement of the spinal cord, which prognosis is largely dependent on early diagnosis and treatment. Reports on this clinical form of schistosomiasis in children are rare in the literature. We present here the clinical-epidemiological profile of schistosomal myeloradiculopathy (SMR) from ten children who were admitted at the Instituto Materno-Infantil de Pernambuco over a five-year period. They were evaluated according to an investigation protocol. Most of these patients presented an acute neurological picture which included as the main clinical manifestations: sphincteral disorders, low back and lower limbs pain, paresthesia, lower limbs muscle weakness and absence of deep tendon reflex, and impairment of the gait. The diagnosis was presumptive in the majority of the cases. This study emphasizes the importance of considering the diagnosis of SMR in pediatric patients coming from endemic areas who present a low cord syndrome, in order to start the appropriate therapy and avoid future complications.

Key words: neuroshistosomiasis - schistosomal myeloradiculopathy - schistosomiasis mansoni - epidemiology

Spinal cord schistosomiasis is a severe presentation of schistosomal infection caused by Schistosoma mansoni and/or S. haematobium. The first species has been identified as the most frequent etiologic agent of schistosomal myeloradiculopathy (SMR) worldwide (Rosemberg \& Arita 1991, Ferrari 1999, 2004).

The nervous lesions in SMR are due to an inflammatory reaction of granulomatous nature to the parasite eggs that are deposited in the spinal cord. A large number of granulomas deposited in circumscribed areas of the nervous system cause lesions due to both the mass effect and the destructive action of the inflammatory reaction on the adjacent nervous tissue. Vasculitis of immune etiology has also been implicated in the genesis of the nervous lesions (Pittella 1985). SMR generally involves the lower portions of the medulla and the roots that form the cauda equine. Probably the disease occurs because the eggs reach the spinal cord through retrograte venous flow into the Batson's venous plexus, which is connected to intra-abdominal veins and drainages the lower regions of the medulla (Galvão 1994, Tedrus et al. 1996). Moreover, the relatively large size of the eggs and the presence of spicules on their shells seem to contribute to their difficulty in progressing along the veins of the epidural plexus (Scringeour \& Gajdusek 1985).

${ }^{+}$Corresponding author: karina@cpqam.fiocruz.br Received 25 May 2006

Accepted 26 June 2006
The onset of SMR may be sudden, rapidly progressive or, exceptionally, insidious. Occasionally, there is a previous record of trauma or physical effort, such as weightlifting, abdominal exercise or evacuation. Such conditions increase the intra-abdominal pressure (Costa et al. 1992, Silva et al. 2004).

The clinical presentation of SMR is very suggestive when observed in individuals who have been exposed to schistosomal infection: low back and/or lower limbs pain (particularly of a radicular nature), followed by progressive motor deficit (paraparesis that may evolve into paraplegia), impairment of lower limbs sensitivity and sphincteral disorders. Paresthesia, abnormal deep tendon reflexes, and sexual impotence are also common findings (Machado 1993, Ferrari 1999, Peregrino et al. 2002, Ferrari et al. 2004, Silva et al. 2004).

Clinical suspicion of SMR is usually not difficult; even though the diagnosis is presumptive in most cases due to the lack of a non invasive confirmatory test. Therefore, the diagnosis is based on the history of contact with water contaminated with $S$. mansoni and the suggestive clinical and laboratory findings, along with exclusion of other entities that manifest with the same symptoms. A definitive diagnosis is provided by the anatomopathological study of the nervous tissue obtained either by biopsy or from postmortem examination (Santos 2001, Valença 2002). Although, the biopsy should be avoided because of the risk of additional damage to the nervous tissue.

According to Tedrus (1996), searching for antibodies against Schistosoma in the cerebrospinal fluid (CSF) is essential in cases of spinal cord disease when the etiology is unknown. The presence of an inflammatory profile 
in the CSF with increased mononuclear cell counts, presence of eosinophils, increased protein concentration and positive immunological reactions strongly suggest the involvement of the nervous system by Schistosoma, along with the clinical findings and the epidemiological commemoratives. Evidence of parasite eggs in feces or rectal biopsy can only provide indirect information, but they are important clues to the diagnosis (Machado 1993, Galvão 1994).

Neuroimaging findings are nonspecific but they reinforce the diagnosis of SMR (Tedrus 1996, Peregrino et al. 2002). Magnetic resonance imaging (MRI) has been considered the most accurate imaging method in the approach of SMR, because of its high sensitivity for diagnosing spinal cord diseases. It enables visualization of micronodules and necrotic and inflammatory lesions (Peregrino et al. 2002).

The clinical treatment of SMR consists of two stages. The first one comprises the use of a corticosteroid (generally dexamethasone, prednisone or methylprednisolone followed by prednisone), administered immediately after the diagnosis, with the aim of reducing the inflammatory reaction and diminishing the damage to the nervous tissue. Just after the beginning of the corticosteroid, the specific medication is administered (oxamniquine or, preferably, praziquantel) in order to eliminate the systemic infection responsible for the neurological process. The destruction of the adult worms in the portal system reduces egg deposition and their embolization through the Batson's venous plexus, preventing additional damage to the spinal cord and allowing clinical improvement. As the outcome of SCS is largely dependent on early diagnosis and therapy, some authors suggest that the treatment should be started immediately in patients with acute myelopathy and positive epidemiology for schistosomiasis, even before the definition of the diagnostic, and while the work up is in progress (Haribhai et al. 1991, Machado 1993, Galvão 1994, Moreira 1998, Paz et al. 2002).

The most critical phase of schistosomal infection is the infancy, because of the most frequent exposure to contaminated water and the immaturity of the immune system. In addition, the involvement of the spinal cord might be related to the practice of physical activities that increase the intra-abdominal pressure (ball-throwing and running, among others) and are commonly performed by children, independent of the socioeconomic factors. Although the reports on SMR due to S. mansoni have been increased around the world, such cases are still rare in children. The aim of the present study is to highlight the clinical-epidemiological profile of SMR during the infancy based on the description of 10 cases admitted at a health unit in Pernambuco.

\section{MATERIALS AND METHODS}

This is a descriptive retrospective study of a case series involving patients aged 2 to 13 years, living or not in the city of Recife, who were admitted to the Instituto Materno-Infantil de Pernambuco (IMIP), between 2000 and 2004.

Data collection was carried out using an evaluation protocol based on Ferrari (1997), after authorization of the study by the Ethics Committee for Human Research of IMIP. Initially, the cases of SMR in children, during the past five years, were searched in the record books of the epidemiological sector of the institution. Then, the dead file services of the emergency department and pediatric ward were asked for locating the medical records of the cases of SMR in children.

The study included all the cases of SMR found in the medical records, including relapses and transferences from other units. Patients with myelopathy of unknown etiology were excluded. The clinical and laboratory data collected were based on the neurological examination and complementary tests carried out in the emergency department and in the pediatric ward. The following data were obtained from the medical records: sex, age, origin, clinical findings, complementary tests, treatment performed, and clinical evolution.

The classification of the onset of neurological signs and symptoms was based on the criteria proposed by Peregrino et al. (2002): acute ( 0 to 8 days), subacute (9 to 30 days), and slow (greater than 30 days).

The clinical forms of SMR were identified according to the clinical presentation: medullary $(\mathrm{M})$ - cases with clinical characteristics that suggest solely (or absolutely predominant) involvement of the spinal cord; myeloradicular (MR) - cases with clinical evidence of medullary and nerve root lesions, particularly the roots that form the cauda equine; and cone and cauda equina (CCE) syndrome - cases which manifestations results from the involvement of the roots of the cauda equine, with or without involvement of the caudal medulla (cone and epicone).

The following criteria were used to assess the response to treatment: complete recovery $(\mathrm{CR})$ that means absence of neurological signs and symptoms; partial recovery without functional limitation (PRWOFL) in the light of objective improvement, with the presence of slight signs and symptoms but without limitations to the daily activities; partial recovery with functional limitation (PRWFL) when there is some improvement, but functional limitations that compromise daily activities persists; and absence of recovery (AR) when no objective or very slight improvement is observed.

The clinical forms of SMR and the patterns of evolution in response to treatment followed the classifications proposed by Ferrari (1997).

The data were organized in tables and graphs using the Microsoft Excel software, and were represented using simple percentage distributions.

\section{RESULTS}

Twelve cases of SMR were found. However, two were excluded because of the lacking of essential data such as epidemiology, initial examinations, specific immunological tests, and treatment performed, and because records in the medical files were related only to the sequelae. The epidemiological data are shown in Table I.

The age range of the 10 patients was 2 to 13 years, mean of 7.3 years and median of 8 years. Most patients $(70 \%)$ were males.

Pernambuco is one of the states with the highest mean prevalence of individuals infected with $S$. mansoni, par- 
ticularly in the so-called Forest Zone and the sugar-cane growing area (Barbosa et al. 2000). In the present study, $40 \%$ of the cases came from a region that is considered to be highly endemic for schistosomiasis (the Forest Zone), while the other $60 \%$ were from areas with isolated outbreaks of the disease. Among the seven patients who reported contact with natural waters, only one $(14.2 \%)$ did not have the habit of bathing in rivers (Table I).

The mean length of time between the first symptom and full development of the neurological picture, in the eight cases which this information was available, was 6.6 days (range 1 to 15 days). The acute presentation was more frequent ( $75 \%)$, followed by the subacute form (25\%) (Table I).

The most frequent signs and symptoms at the onset of the condition were: (1) lower limb muscle weakness in $100 \%$ of the cases (this was predominantly asymmetric); (2) low back and/or lower limbs pain in $88.8 \%$ (taken into account the nine patients in whom this symptom was investigated); (3) urinary disorders in $70 \%$ of the patients (50\% presented retention and $20 \%$, urinary incontinence); (4) paresthesia in 50\% (considering the four patients who were evaluated for this symptom); and (5) fecal retention in $40 \%$ of the patients (Table II). It should be noted that paresthesia is a sensitivity disorder; therefore its evaluation in children is difficult, and for this reason its fre- quency may be underestimated.

It is important to emphasize that cases 1, 2, and $7(30 \%)$ had already presented paraplegia upon admission, while cases 6 and $9(20 \%)$, initially presented paraparesis that rapidly evolved into paraplegia. On the other hand, 50\% of the cases presented only gait disturbances as a consequence of less intense muscle strength impairment or pain in the lower limbs; thus, they required external assistance for walking.

Alterations of the deep tendon reflexes were observed in the majority of the patients. As detailed in Table III, reduced patellar and Achillean reflexes were observed in $55.6 \%$ of the nine patients in whom the deep tendon reflexes were evaluated. In addition, absences of patellar and Achillean reflexes were found in 33.3 and $44.4 \%$, respectively. Among the nine children in whom the deep tendon reflexes were investigated, there was only one case with no impairment of the patellar and Achillean reflexes. The abdominal reflex, which was evaluated in only three patients, was absent in $66.6 \%$.

Sensory impairment was investigated in nine cases: hypoestesia was observed in $77.7 \%$ and anesthesia in only $22.2 \%$. Sensitive level was recorded in only three medical files, probably because of the difficulty in obtaining such data from children. Given that the level of the lesion (the most rostral medullary segment that is associ-

TABLE I

Epidemiological data of the 10 children, Instituto Materno-Infantil de Pernambuco (2000 to 2004)

\begin{tabular}{rlccclcr}
\hline No. & Initials & Sex & $\begin{array}{c}\text { Age } \\
\text { (years) }\end{array}$ & $\begin{array}{c}\text { River } \\
\text { bathing }\end{array}$ & Region of origin & $\begin{array}{c}\text { Endemic } \\
\text { region }\end{array}$ & $\begin{array}{c}\text { Early progression } \\
\text { (days) }\end{array}$ \\
\hline 1 & JESS & M & 4 & + & Santa Cruz Surubim & - & 15 \\
2 & KFS & M & 10 & UD & Gameleira & + & - \\
3 & DDS & M & 3 & + & Garanhuns & + & 6 \\
4 & JESF & F & 2 & - & Catende & + & UD \\
5 & LDO & M & 8 & + & Cortês & - & 4 \\
6 & JFS & F & 9 & + & Cabo de Santo Agostinho & - & 6 \\
7 & IEFA & M & 8 & + & Araçoiaba & - & + \\
8 & ACBS & F & 10 & UD & Igarassu & + & 1 \\
9 & EJSJ & M & 13 & + & Timbaúba & - & 2 \\
10 & SMR & M & 6 & UD & Machados & & - \\
\hline
\end{tabular}

F: female; M: male; UD: unavailable data; -: negative; +: positive.

TABLE II

Initial symptoms found in the 10 children, Instituto Materno-Infantil de Pernambuco (2000 to 2004)

\begin{tabular}{|c|c|c|c|c|c|c|}
\hline No. & Urinary disorder & $\begin{array}{l}\text { Fecal } \\
\text { retention }\end{array}$ & $\begin{array}{l}\text { Low-back and/or } \\
\text { lower limbs pain }\end{array}$ & Paresthesia & Motor deficit & $\begin{array}{r}\text { Lower limbs } \\
\text { weakness }\end{array}$ \\
\hline 1 & Retention & - & UD & UD & + & + \\
\hline 2 & - & - & + & - & + & + \\
\hline 3 & - & - & + & UD & + & + \\
\hline 4 & Incontinence & + & + & UD & + & + \\
\hline 5 & Retention & + & + & UD & + & + \\
\hline 6 & Retention & - & + & UD & + & + \\
\hline 7 & Incontinence & + & + & - & + & + \\
\hline 8 & - & - & + & UD & + & + \\
\hline 9 & Retention & - & - & + & + & + \\
\hline 10 & Retention & + & + & + & + & + \\
\hline
\end{tabular}

UD: unavailable data; -: absent; +: present. 
ated with the clinical signs and/or symptoms) is largely defined by the sensitive level, the level of the lesion was determined in only $30 \%$ of the sample (T4-T5, L4-L5, and T10, respectively) (Table III).

The description of the clinical forms was impaired in the present study because of the lack of important data, such as the sensitivity level. In an attempt to classify the findings according to the forms proposed by Ferrari (1997), the MRI findings (Table IV) were taken into consideration, together with the clinical manifestations. The myeloradicular form (MR) was the most frequent, accounting to $90 \%$ of the cases, while only one case (case 3) presented the cone and cauda equine (CCE) syndrome. This latter case was classified considering the MRI findings, which demonstrated thickening of the roots that form the cauda equine, and the physical examination.

In the present study, MRI, in general, showed enlargement of the spinal cord with thickening of the roots of the lower thoracic medulla (T8 to T12) and cauda equine, and hyperintensity of the signal (Table IV) that is compatible with the inflammatory nature of the disease (radiculomyelitis). Out of the seven patients who underwent thoracolumbar MRI, $85.7 \%$ presented abnormalities. Case 3 was the only one which lesions were restricted to the cauda equine roots. In case 4 the findings were inconclusive.
Although, it is important to point out that the exam was restricted to the thoracolumbar region; therefore, it is impossible to exclude lesions in the lumbossacral medulla.

Stool parasitological examination was performed in only six cases. S. mansoni eggs were found in the feces of four patients $(66.6 \%$; cases $6,7,8$, and 10$)$, while they were absent in the other two cases (33.3\%; cases 1 and 4 ). In case 1, only one sample of feces was examined, which does not permit to rule out the diagnosis of schistosomiasis. No rectal biopsy was performed. This method should have been shown the presence of eggs in the cases whose parasitological examination of the feces were negative.

Search for anti-Schistosoma antibodies in the CSF using the indirect immunofluorescence (IF) test was performed in eight cases, with positive results in $50 \%$. The ELISA test was performed in the CSF of only three patients, with positive result in two cases $(66.6 \%)$. It should be emphasized that these two cases had previous negative IF test, which is compatible with the higher sensitivity of the ELISA technique.

The diagnosis of SMR in our investigation was based on the clinical and laboratory data described above. Therefore, it was presumptive.

In the present study $50 \%$ of the cases (cases $2,6,7,8$, and 10) were treated with prednisone and oxamniquine,

TABLE III

Physical examination and clinical forms of the 10 children, Instituto Materno-Infantil de Pernambuco (2000 to 2004)

\begin{tabular}{cccccccc}
\hline No. & $\begin{array}{c}\text { Patellar } \\
\text { reflex }\end{array}$ & $\begin{array}{c}\text { Achillean } \\
\text { reflex }\end{array}$ & $\begin{array}{c}\text { Cutaneous- } \\
\text { plantar reflex }\end{array}$ & $\begin{array}{c}\text { Abdominal } \\
\text { reflex }\end{array}$ & $\begin{array}{c}\text { Hypoesthesia } \\
\text { /anesthesia }\end{array}$ & $\begin{array}{c}\text { Level of } \\
\text { the lesion }\end{array}$ & $\begin{array}{c}\text { Clinical } \\
\text { form }\end{array}$ \\
\hline 1 & $\downarrow$ & $\downarrow$ & Flexor & ND & + & T4-T5 & MR \\
2 & $\downarrow$ & $\downarrow$ & Flexor & ND & - & ND & MR \\
3 & $\mathrm{n}$ & $\downarrow$ & ND & - & + & CCE \\
4 & - & - & Flexor & - & + & L4-L5 & MR \\
5 & $\mathrm{n}$ & $\mathrm{n}$ & Flexor & ND & + & ND & MR \\
6 & $\downarrow$ & - & ND & ND & + & T10 & MR \\
7 & - & - & ND & ND & ND & ND & MR \\
8 & $\uparrow$ & - & Flexor & n & - & ND & MR \\
9 & ND & ND & ND & ND & ND & MR \\
10 & - & $\downarrow$ & Flexor & ND & + & ND
\end{tabular}

ND: no data; -: absent; +: present; $\downarrow$ : decreased; $\uparrow:$ increased; n: normal; MR: myeloradicular; CCE: cone and cauda equina.

TABLE IV

Complementary tests of the 10 children performed during hospitalization, Instituto Materno-Infantil de Pernambuco (2000 to 2004)

\begin{tabular}{|c|c|c|c|c|}
\hline \multirow[b]{2}{*}{ Number } & \multirow{2}{*}{$\begin{array}{l}\text { Stool parasitological } \\
\text { examination }\end{array}$} & \multicolumn{2}{|c|}{ Cerebrospinal fluid } & \multirow[b]{2}{*}{ MRI } \\
\hline & & IF & ELISA & \\
\hline 1 & Negative (1/1) & No reaction & Reaction & ND \\
\hline 2 & ND & Reaction & ND & Abnormal (T10-L1) \\
\hline 3 & ND & Reaction & ND & Abnormal (cauda equine) \\
\hline 4 & Negative $(6 / 6)$ & Reaction & ND & Normal \\
\hline 5 & ND & ND & ND & Abnormal (T12-L1) \\
\hline 6 & Positive & No reaction & ND & Abnormal (T11-cone) \\
\hline 7 & Positive & Reaction & No reaction & ND \\
\hline 8 & Positive & ND & ND & ND \\
\hline 9 & ND & No reaction & Reaction & Abnormal (T8-cone) \\
\hline 10 & Positive & No reaction & ND & Abnormal (T9-L1) \\
\hline
\end{tabular}

ND: no data; IF: indirect immunofluorescence test; MRI: magnetic resonance imaging. 
while 20\% (cases 4 and 5) received three drugs and 30\% (cases 1, 3, and 9) received only the corticosteroid (Figure). Physical therapy was prescribed to four patients in the present study, but only two of them (cases 4 and 7) are known to undergo to such treatment. There is no dada in the medical records of the two other cases regarding this therapeutic modality. It is possible that these patients may have not been submitted to physical therapy, because of its neglect in clinical practice.

The outcome of the patients is described in Table V. Case 6 had complete recovery $(11.1 \%) ; 66.6 \%$ of the cases $(1,2,4,7,8$, and 10$)$ had partial recovery without functional limitation; and $22.2 \%$ (cases 5 and 9 ) had partial recovery with functional limitation. In case 3 , it was not possible to evaluate the response to the treatment because of lack of the data.

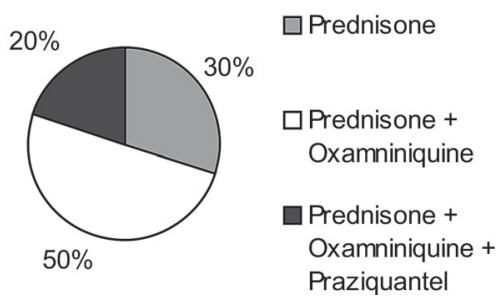

Medical treatment performed in the 10 children, Instituto MaternoInfantil de Pernambuco (2000 to 2004)

\section{TABLE V}

Outcome of nine children, Instituto Materno-Infantil de Pernambuco (2000 to 2004)

\begin{tabular}{lc}
\hline Outcome & $\mathrm{n}(\%)$ \\
\hline $\begin{array}{l}\text { Complete recovery } \\
\text { Partial recovery without functional limitation }\end{array}$ & $1(11.1)$ \\
(PRWOFL) & $6(66.6)$ \\
$\begin{array}{l}\text { Partial recovery with functional limitation } \\
\text { (PRWFL) }\end{array}$ & $2(22.2)$ \\
Absence of recovery & $0(0.0)$ \\
\hline
\end{tabular}

\section{DISCUSSION}

Published studies demonstrate that SMR is more frequent in young adults. Silva et al. (2004), in a review of the literature, reported that the ages of the individuals affected by SMR ranged from 1 to 68 years, with a mean of 26 years. In a clinical and laboratory analysis of 80 cases, Peregrino et al. (2002) pointed out that there were records of 11 children aged 5 to 12 years, and that both the adult and child cases were predominantly in males. Moreira (1998), in an investigation, which methodology was similar to that employed in the present study, reported 12 children (aged 2 to 13 years; mean 8.9 and median 9.5 years) predominantly of the male sex, who were admitted at a hospital in Recife, over a five-year period. These dada are in agreement with ours.

It is believed that the higher incidence of SMR among male children is due to the more frequent exposure to schistosomes. Although there are only a few studies relating to children, there is a clear predominance of the male sex, which may be related to the type of work, habits (bathing in rivers and lakes) and greater exertion (Santos et al. 2001, Nobre et al. 2001).

Most of our patients had the habit of bathing in rivers, but according to Costa et al. (1992), even if the contacts with contaminated water are rare, the possibility of the infection could not be ruled out, since the epidemiological history is variable.

In general, the signs and symptoms of SMR appear and progress acutely. Moreira (1998) reported that the mean length of time between onset and full development of the neurological picture was 11 days, with a range of 6 to 20 days. In our study, the acute form of the disease was much more frequent (91.7\%), followed by the subacute one (8.3\%). Rosemberg and Arita (1991) also observed an acute onset of the disease in $83.3 \%$ of the six cases of SMR in children. Among the 80 cases reported by Peregrino et al. (2002), the subacute form predominated $(61.2 \%)$, followed by the acute one $(25 \%)$ and the slow form $(7.5 \%)$.

SMR can develop at any time following the start of oviposition. However, the vast majority of the cases reported have been observed in the initial phases of the infection (non-toxemic form), during the evolution of the disease to the chronic forms, or concomitantly with the mild chronic (intestinal or hepatointestinal) forms (Pittella 1997, Ferrari 1999). Cases reported during or immediately after the toxemic form, or in association with the hepatosplenic form are rare (Pittella 1997, Matas 2001).

In general, the main signs and symptoms of SMR are: lower limbs muscle weakness, low back and/or lower limbs pain, urinary disorders, paresthesia, sensory deficit, and fecal retention (Rosemberg \& Arita 1991, Lima 1998, Ferrari 1999, Santos et al. 2001, Silva et al. 2004, Ferrari et al. 2004), as observed in our investigation. Moreira (1998) presented the following findings: motor deficit $(100 \%)$, urinary disorders $(100 \%)$, low back pain $(54.5 \%)$, fecal retention $(50 \%)$, and paresthesia $(25 \%)$. Regarding the muscle strength, $75 \%$ of his patients presented paraparesis, while the other $25 \%$ were paraplegic.

Alterations of the patellar and the Achillean reflexes were observed in the majority of the patients included in the present investigation. In most published studies, the main abnormalities of the deep tendon reflexes were arreflexia followed by hyporreflexia, normal reflex and hyperreflexia of the patellar and the Achillean reflexes (Rosemberg \& Arita 1991, Lima 1998, Paz et al. 2002). In Santos et al. (2001), patellar and Achillean arreflexia were observed in $41.1 \%$ and $54 \%$ of the cases, respectively.

Although the level of the lesion was only precisely defined in a very small number of our cases, these findings are agreement with the literature data that demonstrate that the most frequent levels are the low thoracic and lumbosacral regions, the medullary cone and the cauda equine. Occasionally, higher levels have been observed, such as T2-T3 (Nobre et al. 2001, Santos et al. 2001, Paz et al. 2002). According to Tedrus et al. (1996), the lesions usually involve the lower portions of the medulla (the cone and cauda equine), and less frequently the dorsolumbar segment. In our sample, the highest level affected was T4, as was found by Koul et al. (2000), in a case study. 
The classification of the clinical forms is still not uniform, which makes the classification of the cases and the comparison of the data difficult. Silva et al. (2004), in a review study, referred to the classical description of four clinical forms: granulomatous, myelitic, radicular and vascular, which take into account the clinical and histopathological aspects, along with the imaging findings on myelography. Ferrari (1997) defined the clinical forms of SMR based on the clinical data, classifying them as described in the topic Materials and Methods: medullary (M), myeloradicular (MR), and cone and cauda equina (CCE) syndrome. According to this classification, the MR form was the most frequent in our cases. Ferrari et al. (2004), in a prospective study of 63 patients, also found a higher frequency of the MR form (54\%) followed by the M one (27\%) and the CCE syndrome (19\%). Santos et al. (2001) identified 31 cases $(55.3 \%)$ with the MR form, while 16 (28.6\%) presented the myelitic one. In a study on 12 cases, Moreira (1998) found six patients (50\%) with the MR form and five (41.7\%), with the myelitic one. Paz et al. (2001) found four subjects $(57.1 \%)$ with the myelitic form and three $(42.9 \%)$ with the pseudotumoral one in a study on seven cases. Although there is no consensus, the MR form predominates in most investigations.

In the present study, six of the seven patients $(85.7 \%)$ who underwent thoracolumbar MRI presented the abnormalities usually observed in this entity. In one case the findings were inconclusive. Although, it is important to point out that the exam in this patient was restricted to the thoracolumbar region; therefore, it is impossible to exclude the presence of lesions in the lumbossacral medulla. In the study by Paz et al. (2001), which included seven children, MRI showed increased diameter of the spinal cord in five patients, predominantly at the thoracolumbar level, while it was normal in one case. On the other hand, Moreira (1998) found abnormalities in only one case among the three children who were submitted to this method. In the study by Peregrino et al. (2002), MRI was performed on 18 patients and increased in the diameter of the medulla, mainly at the T11-T12 and/or the L4-L5 levels, was found in $88.8 \%$ of the cases.

S. mansoni eggs are found in the great majority of the cases of SMR. In our study shistosomal eggs were found in the feces of more than half of the patients. Moreira (1998) reported presence of eggs in the feces of $50 \%$ of the six children whose feces were examined, and in the rectal mucosa of $100 \%$ of the two cases submitted to rectal biopsy. Nobre et al. (2001) reported the presence of eggs in four $(36 \%)$ of the eleven patients whose feces were analyzed, while eggs were detected in the rectal biopsy of the $19(100 \%)$ patients submitted to this procedure. In the 29 cases studied by Asano (1992), 11 (38\%) had eggs in the feces and in the study by Lima (1998), the stool parasitological examination was negative in $91 \%$ of the 21 patients studied. Ferrari et al. (2004) found eggs in the feces (three to five samples collected, on different days) from only $32(59.2 \%)$ of the 54 patients evaluated, while rectal biopsy was positive in $56(88.9 \%)$ of 63 cases. Quantitative oogram analysis showed fewer than 1000 eggs/g of tissue in $71.6 \%$ of these cases, which is compatible with low parasite load. In view of this finding, these authors suggested that SMR is a severe form of presentation of schistosomiasis that is unrelated to the parasitic burden. Irregular distributions of the eggs in the feces along with low concentrations of eggs in the cases of low parasite burden are factors that may lead to diagnostic failure of the stool parasitological examination (Asano 1992, Moreira 1998).

The most promising laboratory test for diagnosing SMR is the investigation of specific antibodies against schistosomal antigens in the CSF by means of IF or ELISA. The latter is more sensitive and more specific (Asano 1992). Our results also suggest that the ELISA test has a better accuracy than the IF technique. Immunological tests have become part of the CSF analyses for suspected cases of SMR, but standardization is still required. Asano (1992) found a positive reaction using the IF examination in $72.4 \%$ of the patients, while the positively was higher using the ELISA reaction (86.2\%). Among the 15 patients studied by Lima (1998), the ELISA test gave a positive reaction in 86\%. In the study by Andrade Filho et al. (1996), IF gave a positive reaction in $50 \%$ of the patients and the indirect hemagglutination test, in 100\%. In Moreira (1998), IF was positive in $62.5 \%$ of the eight cases, while the ELISA test gave a positive reaction in $40 \%$ of the five cases. On the other hand, Paz et al. (2002) found a positive IF reaction in $28.5 \%$ of the cases and a positive ELISA test in $71.4 \%$. Pammenter et al. (1991) employed the ELISA technique to investigate $\mathrm{IgG}$ against soluble egg antigen of $S$. mansoni (IgG anti-SEA) in the CSF of 12 patients with SMR and 146 individuals with myelopathy of other etiologies. The test gave a positive result in 25 patients, and all the cases of SMR were included in ELISA positive group. IgG antiSEA was also investigated using the ELISA technique in the CSF from 54 patients with SMR and 41 controls with other diseases of the central nervous system by Ferrari et al. (1995), who found a sensitivity of $56 \%$ and a specificity of $95 \%$ for this test.

The diagnosis of SMR is generally presumptive. Peregrino et al. (2002) reported only one case, among 80 patients, whose diagnosis was confirmed by the anatomopathological examination. Demonstration of $S$. mansoni eggs in the nervous tissue obtained by biopsy or necropsy is the only uncontestable proof of SMR. However, biopsy is an invasive diagnostic procedure that can cause additional damage to the inflamed nervous tissue; therefore, it should be avoided.

Santos et al. (2001) suggested criteria for diagnosing SMR. According to these, a possible diagnosis could be done when the lower thoracic or the lumbosacral medulla is involved and there is positive epidemiology for $S$. mansoni infection; a probable diagnosis is considered when the above factors are present and the stool parasitological examination and/or the rectal biopsy disclose eggs of $S$. mansoni; and a proven diagnosis when, in addition to the above factors, there are $S$. mansoni eggs in the nervous tissue obtained by biopsy. In the present study, possible diagnosis was the most frequent $(62.5 \%$; cases $1,2,3,4$, and 5), followed by probable diagnosis (37.5\%; cases 6, 7, and 9). According to the criteria by Santos et al. (2001), cases 8 and 10 remained unclassified, because of the lack of some data. 
In the absence of the anatomopathological proof, the diagnosis of SMR is based on clinical and laboratory criteria. When a child presents with an acute myeloradicupathy, the schistosomal etiology should be investigated, whether or not the child comes from an endemic zone, and even in the absence of clinical symptoms of abdominal viscera involvement, due to the fact that the outcome is largely dependent on early and appropriate therapy (Rosemberg \& Arita 1991).

A corticosteroid associated with an antischistosomal agent is considered the treatment of choice of SMR (Rosemberg \& Arita 1991, Haribhai et al. 1991, Ferrari 1999, Paz et al. 2002, Silva et al. 2004, Ferrari et al. 2004). Although some response to the clinical treatment is usually observed, many cases do not present complete recovery. In the study by Nobre et al. (2001), which included 23 SMR patients, partial recovery without functional limitation was observed in the majority of the patients $(56.5 \%)$, followed by complete recovery $(21.7 \%)$, and partial recovery with functional limitation or absence of recovery (17.4\%). Paz et al. (2001), in a study which included six children, observed full recovery in only two of them and partial recovery in four.

The good response to the clinical treatment suggests the efficacy of the antischistosomal drug in destroying the adult worms, thereby avoiding new oviposition. Moreover, corticosteroids reduce the inflammatory process in the spinal cord which diminishes the lesions of the nervous tissue. However, sequelae and complications such as scars, urinary infections, sphincteral abnormalities (especially bladder dysfunction), lower limbs muscle weakness, paresthesia and radicular pain are common (Andrade Filho et al. 1996, Koul et al. 2002).

We emphasize the importance of considering schistosomiasis in the differential diagnosis of pediatric patients with myeloradicular manifestations, mainly if they come from areas where schistosomiasis is endemic, in order to start the appropriate treatment as earlier as possible in order to allowing a better outcome and avoiding future complications.

\section{REFERENCES}

Asano NMJ 1992. Neuroesquistossomose: Aspectos Clínicos, Laboratoriais e de Imunodiagnóstico, MSc Thesis, Universidade Federal de Pernambuco, Recife, 119 pp.

Andrade Filho AS, Dos Reis MG, Souza AL, Martins ER, Santos, SRS, Ancilon M, Lima JMPF, Queiroz AC, Guimarães MGM, Moreno-Carvalho AO, Rego MF 1996. Neuroesquistossomose mansônica: aspectos clínicos, laboratoriais e terapêuticos. Arq Neuropisquiatr 54: 232-237.

Barbosa CS, Pieri OS, Silva CB, Barbosa FS 2000. Ecoepidemiologia da esquistossomose urbana na Ilha de Itamaracá, Estado de Pernambuco. Rev Saúde Públ 34: 337-341.

Costa RO, Gameleira FT, Tenório RB, Brás LH, Costa VB, Pinto Jr JM 1992. Neuroesquistossomose em Alagoas. Rev Bras Neurologia 28: 79-84.

Ferrari TCA 1997. Abordagem Diagnóstica da Mielorradiculopatia Causada pelo Schistosoma mansoni: Imunodiagnóstico em Líquor pela Técnica de Elisa, $\mathrm{PhD}$
Thesis, Universidade Federal de Minas Gerais, Belo Horizonte, $207 \mathrm{pp}$.

Ferrari TCA 1999. Spinal cord schistosomiasis: a report of 2 cases and review enphasizing clinical aspects. Medicine 78 : 176-190.

Ferrari TCA 2004. Involvement of central nervous system in the schistosomiasis. Mem Inst Oswaldo Cruz 99 (Suppl. I): 59-62.

Ferrari TCA, Moreira PRR, Cunha AS 2004. Spinal cord schistosomiasis: a prospective study of 63 cases emphasizing clinical and therapeutic aspects. J Clin Neurosci 11: 246253.

Ferrari TCA, Moreira PRR, Oliveira RC, Ferrari MLA, Gazzinelli G, Cunha AS 1995. The value of an enzymelinked immunosorbent assay (ELISA) for the diagnosis of schistosomal mansoni myeloradiculopathy. Trans $R$ Soc Trop Med Hyg 89: 496-500.

Galvão ACR 1994. Como eu trato a neuroesquistossomose. In LR Machado, Neuroinfecção: Como eu Trato Neuro-esquistossomose, Clínica Neurológica HC/FMUSP, São Paulo, p. 264-268.

Haribhai HC, Bhigjee AI, Bill PLA, Pammenter MD, Modi G, Hoffmann M, Kelbe C, Becker P 1991. Spinal cord schistosomiasis: a clinical, laboratory and radiologic study, with a note on therapeutic aspects. Brain 114: 709-726.

Koul R, Alexander P, Scrimgeour E, Idris M, Joseph K 2002. Shistosoma mansoni myeloradiculopathy in an 8-year-old omani boy. J Trop Pediatr 48: 183-186.

Lima AC 1998. Neuroesquistossomose: Estudo Descritivo de 31 Casos do Serviço de Neurologia do Hospital da Restauração, Monograph, Recife, $32 \mathrm{pp}$.

Moreira MASA 1998. Neuroesquistossomose Medular na Infância - Estudo de 12 Casos, Monograph, Recife, 31 pp.

Machado LR 1993. Esquistossomose do sistema nervoso. In R Nitrini, LR Machado (eds), Condutas em Neurologia, Editora Associados, São Paulo, p. 129-132.

Matas SLA 2001. Neuroesquistossomose. Rev Neurociencias 9: 27-31.

Nobre V, Silva LCS, Ribas JG, Rayes A, Serufo JC, Lana-Peixoto MA, Marinho RFZ, Lambertucci JR 2001. Schistosomal myeloradiculopathy due to Schistosoma mansoni: report on 23 cases. Mem Inst Oswaldo Cruz 96: 137-141.

Pammenter MD, Haribhai HC, Epstein SR, Rossouw EJ, Bhigjee AI, Bill PLA 1991. The value of immunological approaches to the diagnosis of schistosomal myelopathy. Am J Trop Med Hyg 44: 329-335.

Paz JA, Valente M, Casella EB, Dias MJM 2002. Spinal cord schistosomiasis in children: analysis of seven cases. Arq Neuropsiquiatr 60: 224-230.

Peregrino AJP, Puglia PMK, Nóbrega JPS, Livramento JA, Marques-Dias MJ, Scaff M 2002. Esquistossomose medular: analise de 80 casos. Arq Neuropsiquiatr 60: 603-608.

Pittella JEH 1985. Vascular changes in cerebral schistosomiasis mansoni: a histopathological study of fifteen cases. Am J Trop Med Hyg 34: 898-902. 
Pittella JEH 1997. Neuroschistosomiasis. Brain Pathol 7: 649662.

Rosemberg S, Arita FN 1991. Mielopatia por esquistossomose mansônica em crianças. Rev Bras Neurol 27: 103-107.

Santos EC, Campos GB, Diniz AC, Leal JC, Rocha MOC 2001. Perfil clínico e critérios diagnósticos da mielorradiculopatia esquistossomótica. Arq Neuropsiquiatr 59: 772-777.

Scrimgeour EM, Gajdusek DC 1985. Involvement of the central nervous system in Schistosoma mansoni and $S$. haematobium infection: a review. Brain 108: 1023-1038.
Silva LCS, Maciel PE, Ribas JGR, Pereira SRS, Serufo JC, Andrade LM, Antunes CM, Lambertucci JR 2004. Mielorradiculopatia esquistossomótica. Rev Soc Bras Med Trop 39: 261-272.

Tedrus GMA, Viana MA, Fonseca LC, Araújo CR 1996. Neuroesquistossomose. Rev Ci Médicas - PUCCAMP 5: 21-23.

Valença MM 2002. Critérios diagnósticos da esquistossomose mansônica meningomielorradicular. Arq Neuropsiquiatria 60: 181-182. 